\title{
Un análisis de los insultos en el Quijote desde la historia social del lenguaje*
}

\author{
JESÚS M. USUNÁRIZ **
}

\section{Resumen}

El uso cotidiano del insulto, de la injuria, en las sociedades de la Edad Moderna, se hace también presente en las voces de los protagonistas de Don Quijote. No obstante, el ingenioso hidalgo y su escudero no hacen un mismo uso del insulto. Este dependerá, en buena parte, de la posición social del insultador y del insultado (hidalgo o villano), y de las circunstancias que lo rodean. No obstante, la realidad social, recogida en diferentes pleitos ante los tribunales, muestra que la injuria no respetaba de la misma forma que en la novela, la estructura estamental.

Palabras Clave: insulto; injuria; Quijote; pleitos judiciales; sociedad española de la Edad Moderna.

Title: An Analysis of Insults in Don Quixote from the Perspective of Social History of Language

\begin{abstract}
Daily use of insult, slander, in the societies of the Early Modern Age, is also present in the voices of the protagonists of Don Quixote. However, the Ingenious Gentleman and his squire, do not use the insult in the same way. This will depend on the social position of insulted and offender (noble or villain), and the circumstances surrounding it. However, social reality, collected in different court cases, shows that the insult did not respect, in the same way as in the novel, the stratified social structure.
\end{abstract}

Key Words: insult; slander; Quixote; court cases; Early Modern Spanish society.

* Este trabajo forma parte de los resultados del proyecto Discurso y poder, lengua y autoridad en el mundo hispánico (siglos XVI-XVII), HAR2012-31536, subvencionado por el Ministerio de Economía y Competitividad.

** GRISO-Universidad de Navarra, Departamento de Historia, Historia del Arte y Geografía. jusunariz@unav.es / ORCID iD: http://orcid.org/0000-0001-5274-2397. 


\section{Cómo citar este artículo / Citation}

Usunáriz, Jesús M. (2017). «Un análisis de los insultos en el Quijote desde la historia social del lenguaje», Anales Cervantinos. 49, pp. 59-73, doi: http://dx.doi.org/10.3989/ anacervantinos.2017.003.

\section{INTRODUCCIÓN}

Peter Burke en su historia antropológica de Italia dedicó algunas de sus páginas al uso del insulto, y fueron varios los trabajos que se centraron posteriormente en el estudio de la injuria. La razón era obvia: el insulto, la injuria, el improperio, podía definirse - como lo hace Burke - como «un acto de comunicación dirigido contra un individuo, grupo o institución» (Burke 1987: 96, 50) ${ }^{1}$. Desde un punto de vista histórico puede ser una clave más para indagar sobre el sistema social de valores vigente. Pero en esta ocasión no nos centraremos ni en aspectos lexicográficos ${ }^{2}$, ni en las consecuencias sociales de la injuria sobre el honor o sobre el estatus ${ }^{3}$, ni en su gran variedad de protagonistas, ni en las circunstancias concretas que las rodean, en donde no faltan los sempiternos odios vecinales, familiares o matrimoniales ${ }^{4}$, cuando no las rivalidades políticas. Esta limitada aproximación al estudio de los insultos, de los "duelos verbales", pretende comparar el uso literario con la práctica cotidiana de la injuria en la sociedad de los siglos XVI y XVII. Para esto utilizaremos y compararemos los resultados extraídos de dos laboratorios: uno, el Quijote ${ }^{5}$, que incluye en sus capítulos numerosos ejemplos de esta violencia verbal6; otro, y más breve, el de los procesos judiciales de los siglos XVI y XVII, los cuales, gracias al testimonio de los principales testigos, casi de forma inmediata a los hechos, relatan lo que han visto y oído y reflejan, a nuestro modo de ver, una realidad social.

\section{1. ¿A QUIÉN INSULTA EL HIDALGO?}

Las más duras y repetidas ofensas de don Quijote de la Mancha van dirigidas no a gigantes y molinos, no a magos ni encantadores, sino a su propio

1. Reflexiones similares en Burke (1989). Sobre este tema ver también Usunáriz (2005).

2. Estudiados para el siglo XVII a partir de procesos inquisitoriales por Tabernero (2010).

3. Puede verse Usunáriz (2016).

4. Sobre el uso del insulto en los pleitos de violencia doméstica, véase Usunáriz (2010) y en los enfrentamientos entre padres e hijos, Usunáriz (2008).

5. Para las citas utilizaremos la edición preparada por Francisco Rico y editada por la Real Academia Española (Cervantes Saavedra, 2004).

6. Jesús Gómez ha destacado la acumulación de insultos entre don Quijote y Sancho, a diferencia de lo que ocurría en las obras pertenecientes al género dialogado (Gómez 2004: 262). Véase especialmente el trabajo de F. Javier Herrero Ruiz de Loizaga (2013). También Torres y Estela-Guillemont (2008: 739-742) han tratado esta violencia verbal y corporal entre caballero y escudero. 
escudero y están lejos de una retórica caballeresca ${ }^{7}$. Como veremos después, a diferencia de Sancho, don Quijote abunda en la utilización de insultos con una "función conativa", es decir, "cuando el hablante profiere el insulto directamente contra su interlocutor" (Castillo Lluch 2004: 24-25). A esta se suma, en ocasiones, una "función expresiva" en donde no faltan las obscenidades. El caballero de la Triste Figura estalla indignado cuando Sancho, rompiendo con el protocolo de la obediencia, exige a su amo que se olvide de Dulcinea y opte por casarse con Dorotea, o mejor, la reina Micomicona, que le promete reinos y gobiernos, y lanza una sarta de improperios avasalladores y avasallantes, que pretenden dejar a Sancho en su lugar:

\begin{abstract}
¿Pensáis - le dijo a cabo de rato-, villano ruin, que ha de haber lugar siempre para ponerme la mano en la horcajadura y que todo ha de ser errar vos y perdonaros yo? Pues no lo penséis, bellaco descomulgado, que sin duda lo estás, pues has puesto lengua en la sin par Dulcinea. ¿Y no sabéis vos, gañán, faquín, belitre que si no fuese por el valor que ella infunde en mi brazo, que no le tendría yo para matar una pulga? Decid, socarrón de lengua viperina, ¿y quién pensáis que ha ganado este reino y cortado la cabeza a este gigante y héchoos a vos marqués, que todo esto doy ya por hecho y por cosa pasada en cosa juzgada, si no es el valor de Dulcinea, tomando a mi brazo por instrumento de sus hazañas? Ella pelea en mí, y vence en mí, y yo vivo y respiro en ella, y tengo vida y ser. ¡Oh hideputa bellaco, y cómo sois desagradecido: que os veis levantado del polvo de la tierra a ser señor de título y correspondéis a tan buena obra con decir mal de quien os la hizo! [Y poco después, cuando Sancho afirma que no podía decir nada sobre la hermosura de Dulcinea, porque no la había visto, cuando en capítulos anteriores había engañado a su amo diciendo que sí, le grita don Quijote:] — ¿Cómo que no la has visto, traidor blasfemo? — dijo don Quijote- . Pues, ¿no acabas de traerme ahora un recado de su parte? ${ }^{8}$ (I, 30).
\end{abstract}

Y estas retahílas se repiten a lo largo de la obra: como cuando don Quijote ordena a Sancho que ensille a Rocinante para que ambos acompañen a la reina Micomicona y la ayuden a recuperar su reino, y el escudero se niega diciendo que la reina no era tal, ante lo que el hidalgo, enfurecido exclama:

¡Oh bellaco, villano, mal mirado, descompuesto, ignorante, infacundo, deslenguado, atrevido, murmurador y maldiciente! ¿Tales palabras has osado decir en mi presencia y en la destas ínclitas señoras y tales deshonestidades y atrevimientos osaste poner en tu confusa imaginación? ¡Vete de mi presencia, monstruo de naturaleza, depositario de mentiras, almario

7. Creo, en este sentido, que los insultos de don Quijote no son «solo en realidad regaños contra las reticencias del escudero a ingresar radicalmente en el copretérito lúdico», ni son solo, como en el caso de los espetados contra el galeote Ginés, una parte de la «retórica caballeresca: insultos rituales para entrar en combate, o para humillar al vencido» (Sheridan 2007: 28).

8. A los insultos habría que añadir, para acentuar el tono del enojo de don Quijote, el cambio del tú al vos (Cash 2008: 228). 
de embustes, silo de bellaquerías, inventor de maldades, publicador de sandeces, enemigo del decoro que se debe a las reales personas! ¡Vete, no parezcas delante de mí, so pena de mi ira! (I, 46).

De esta forma, es tal la cantidad de improperios directos que lanza el Quijote, colérico en muchas ocasiones, a lo largo de su obra, por lo que el pobre Sancho hace o no hace, dice o no dice, cuenta o no cuenta, que podemos permitirnos establecer una tipología de los insultos directos, humillantes, recibidos por el escudero manchego.

Estos afectan a su inteligencia: "necio" (I, 25, 31), "de ingenio boto" (I, 25), "majadero" (I, 30), "simple" (I, 31), "loco" (I, 37), "mentecato" (I, 37; II, 43). "ignorante" (I, 46; II, 43, 66), "infacundo" (I, 46), "prevaricador del buen lenguaje" (II, 19), "pan mal cocido" (II, 28), "bestia" (II, 28, 62), "asno eres y asno has de ser y en asno has de parar"9 (II, 28), "tonto" (II, 31, 32, 34, 41, 58), "bobo" (II, 32). A su aspecto físico: "monstruo de naturaleza" (I, 46); "glotón" (II, 20, 66); "vestiglo" (II, 28), "tragón” (II, 62). A su condición social 10: "villano ruin", "villano", "grosero villano" (I, 20, 30, 46; II, 20, 31), "villano harto de ajos" (II, 35), "porro" (II, 42). Y, en general, a su comportamiento con él y con quienes le rodean: "grande hablador" (I, 25), "deslenguado" (I, 46), "murmurador" (I, 46), "maldiciente" (I, 46), "depositario de mentiras", "almario de embustes", "silo de bellaquerías", "inventor de maldades" (I, 46), "mentiroso" (I, 37) "mayor bellacuelo que hay en España" (I, 37), "ladrón" (I, 37; II, 41), "vagamundo" (I, 37), "atrevido" (I, 46), "traidor" (II, 17, 62), "bergante" (II, 17), "maldito" (II, 17), "prevaricador de las ordenanzas escuderiles" (II, 28), "malandrín" (II, 28), "follón" (II, 28), “cobarde" (II, 31, 41), "animal descorazonado" (II, 41).

En consecuencia, el protagonista de la novela cervantina se muestra a sí mismo como un superior. El uso del insulto con las funciones conativa y expresiva, por su carácter directo, desnudo de matices, refuerza en el lector la imagen de un hidalgo que, a pesar de su locura, no pierde de vista el lugar que ocupa como tal noble o como caballero, tanto en una sociedad real, como en el mundo imaginado de la caballería andante ${ }^{11}$.

Pero este mismo tono directo, de superioridad, que usa don Quijote en sus retahílas de insultos, se aplica también hacia otros personajes, según considera él mismo, de calidad inferior. Arrieros, venteros, mesoneros, cabreros, molineros, pastores, locos, cuadrilleros, labradores, salteadores de caminos, galeotes, cuando no gigantes, magos o encantadores, son la "gente soez, mal-

9. Kudaka Watanabe (1999) realiza un interesante análisis del proceso de «asnificación» de Sancho.

10. Insultos como «ruin villano» son, en palabras de Sheridan (2007: 31): «recordatorio de su calidad de criado».

11. Gómez (2004) ha destacado la progresiva importancia de los diálogos entre Quijote y Sancho, y como se revela en ellos «el desnivel social entre amo y criado». Pero también los insultos del caballero a su escudero son la respuesta airada al «perspectivismo que Sancho introduce mediante sus pláticas». 
nacida", "villanos", "bellacos", "follones" y "malandrines". Es su locura la que le "permite" atacar a unos pobres frailes de San Benito, convertidos en "gente endiablada o descomunal", "fementida canalla" (I, 8), o despreciar al vizcaíno por no ser caballero (I, 8). Pero, como se puede comprobar, el hidalgo sabe guardar la compostura social de la que forma parte y que respeta, pues tales insultos no alcanzan a aquellos grupos sociales que están por encima de él o, incluso, a sus iguales, sean sus personajes auténticamente de mayor calidad o porque así se la atribuye la imaginación del enajenado caballero.

Y un último aspecto de este apartado: ¿insulta don Quijote a don Quijote? Nunca. Solo al final, en su lecho de muerte se dirige a su sobrina y le dice:

Yo me siento, sobrina, a punto de muerte; querría hacerla de tal modo, que diese a entender que no había sido mi vida tan mala que dejase renombre de loco, que puesto que lo he sido, no querría confirmar esta verdad en mi muerte (II, 74).

Entonces y solo entonces, a las puertas de la eternidad, Quijote es capaz de reconocerse a sí mismo como el loco que ha sido a los ojos del mundo.

\section{2. ¿A QUIÉN INSULTA SANCHO?}

En muy escasas ocasiones podremos encontrar en Sancho insultos con una función conativa hacia su amo don Quijote. En todos los casos, los insultos de Sancho hacia el hidalgo tienen un valor referencial ("denotativo, informativo") (Castillo Lluch 2004: 24-25), pues no se dirigen a él, a su "señor natural" sino a través de una tercera persona. En la conversación que Sancho mantiene con el escudero del caballero del Bosque le dice en confianza:

... y el rato que en esto pienso se me hacen fáciles y llevaderos cuantos trabajos padezco con este mentecato de mi amo, de quien sé que tiene más de loco que de caballero (II, 13).

Y añade, moderando su opinión, tras escuchar el sentir del otro escudero sobre su propio amo,

... podré consolarme, pues sirve a otro amo tan tonto como el mío. [A lo que responde el escudero del Bosque] Tonto, pero valiente, - respondió el del Bosque-, y más bellaco que tonto y que valiente. [Y responde Sancho:] Eso no es el mío - respondió Sancho-: digo, que no tiene nada de bellaco; antes tiene una alma como un cántaro: no sabe hacer mal a nadie, sino bien a todos (II, 13).

Es este tono referencial el que utiliza Sancho a lo largo de las dos partes de la novela en sucesivos testimonios, como en uno de sus soliloquios: «Este 
mi amo, por mil señales, he visto que es un loco de atar, y aun también yo no le quedo en zaga, pues soy más mentecato que él, pues le sigo y le sirvo» $(\mathrm{II}, 10)^{12}$; mientras camina junto a él y le cuenta a su señor lo que dicen de ellos: «Pues lo primero digo — dijo — es que el vulgo tiene a vuestra merced por grandísimo loco, y a mí por no menos mentecato. [Y añade más adelante]: En lo que toca — prosiguió Sancho - a la valentía, cortesía, hazañas y asumpto de vuestra merced, hay diferentes opiniones; unos dicen "loco, pero gracioso"; otros "valiente, pero desgraciado"; otros, "cortés, pero impertinente"» (II, 2); o cuando habla en privado con la duquesa: «Lo primero que digo es que yo tengo a mi señor don Quijote por loco rematado [...] a mi se me ha asentado que es un mentecato» (II, 33).

Solo en dos ocasiones el insulto de Sancho a don Quijote es directo, tiene esa función conativa. Una de ellas constituye el único denuesto que dirige Sancho a su amo en la primera parte. Se produce cuando el criado procura convencer al hidalgo que va enjaulado de que aquello no era cosa de encantamientos, sino una estratagema del cura y del barbero para llevarlo a su casa. Ante la resistencia del caballero a creerlo le espeta, casi desesperado ante la obcecación malsana de su amo:

$\mathrm{Y}$, ¿es posible que sea vuestra merced tan duro de celebro, y tan falto de meollo, que no eche de ver que es pura verdad la que le digo? (I, 48).

La otra se produce en la segunda parte: es la de un Sancho a la defensiva que, atemorizado y trémulo ante la amenaza de que su amo lo azote para acabar con el maleficio que ensombrecía la figura de Dulcinea, se resiste, arremete — ¡hecho inusitado! — contra él, le exige la promesa de que no le azotará y le grita y amenaza: "Donde no, aquí morirás traidor, enemigo de doña Sancha" (II, 60).

No falta tampoco en Sancho una tercera función del insulto, a caballo entre su carácter conativo y expresivo, en donde ya no tiene ese alcance peyorativo, y se convierte en algo casi elogioso. Cuando don Quijote narra a Sancho las apasionadas propuestas amorosas que le había dirigido la bella Altisidora en el palacio de los duques, y que fueron rechazadas por su firme amor hacia Dulcinea, Sancho se mostrará, con tono cómplice y travieso, entre sorprendido y maravillado:

— ¡Crueldad notoria! — dijo Sancho—. ¡Desagradecimiento inaudito! Yo de mi sé decir que me rindiera y avasallara la más mínima razón amorosa suya. ¡Hideputa y qué corazón de mármol, qué entrañas de bronce y qué alma de argamasa! Pero no puedo pensar qué es lo que vio esta doncella en vuestra merced (II, 58) ${ }^{13}$.

12. Y lo repite después, II, 36.

13. Este mismo tono aparece en el diálogo que mantiene Sancho con el escudero del Bosque. Este, cuando se refiere a la hija de Sancho de quince años y dice: «iOh hideputa, puta, y qué rejo debe de tener la bellaca!». A lo que Sancho replica «mohíno»: «Ni ella es puta ni lo fue su madre 
En todo caso, y salvo dos esporádicos momentos, Sancho se muestra respetuoso hacia su amo, mantiene el decoro del labrador hacia el hidalgo, a quien respeta y admira a pesar de todo: del mal comer, del mal dormir, de los malos caminos, de los palos repetidos. No es solo la "laudable indiferencia" (Sheridan 2007: 31) del que se define como "hombre pacífico, mano y sosegado" $(\mathrm{I}, 15)^{14}$, sino que asienta, con su actitud, el distanciamiento social y honorífico propio de la sociedad estamental en la que vive.

Es más, a diferencia de su amo, Sancho se ríe de su persona y de lo que representa, se impreca en repetidas ocasiones a lo largo de toda la obra, con la naturalidad que le da su simpleza, ejerciendo así su emérito papel de gracioso. Sancho se define, pues, a sí mismo, como "zafio y villano" (I, 23), "asno" (I, 25), "soy algo malicioso", con "asomos de bellaco" (II, 8), "bestia" (II, 13), "mezquino y malaventurado" (II, 13), "mostrenco" (II, 32; II, 51), de "ruin ingenio", "malévolo" (II, 33), "porro" (II, 45); "testarudo" (II, 53), “tonto" (II, 55; II, 73), "tragantón” y “comilón” (II, 59).

Ahora bien, ¿cuándo se muestra Sancho más envalentonado, más confiado a la hora de insultar? Desde luego, cuando se convierte en juez y gobernador de la ínsula de Barataria por delegación de los duques, y se hace con la autoridad necesaria que le permitirá insultar desde la tarima imponente de su cargo, recuperando la función conativa del improperio. Ante la mujer que acude a él, quejosa de haber sido mancillada por un ganadero, pero que, en realidad, había sido pagada por ello como vulgar buscona, y tras una astuta estratagema del juez Panza, se verá finalmente desterrada de la ínsula bajo los insultos de: "Andad luego, digo, churrilera, desvergonzada y embaidora" (II, 45). Ante las persistentes recomendaciones del latoso doctor Pedro Recio, médico del gobernador, Sancho lo trata de "mal médico, verdugo de la república" (II, 47). Ante el pedigüeño e impertinente labrador que le solicitó dinero para la dote de su hijo, responde un airado Sancho:

- ¡Voto a tal, don patán rústico y mal mirado, que si no os apartáis y ascondéis luego de mi presencia, que con esta silla os rompa y abra la cabeza! Hideputa bellaco, pintor del mesmo demonio, ¿y a estas horas te vienes a pedirme seiscientos ducados?, y ¿dónde los tengo yo, hediondo?; y ¿por qué te los había de dar, aunque los tuviera, socarrón y mentecato? [...] Tú

[...] Y háblese más comedidamente». Y el del Bosque le explica que «aquello que parece vituperio, en aquel término, es alabanza notable». Y poco después, cuando tras beber un largo e interminable trago de vino que le ofrece el del Bosque, Sancho exclama: «¡Oh hideputa bellaco, y cómo es católico!», aquel le recuerda: «¿Véis ahí — dijo el del Bosque, en oyendo el hideputa de Sancho_, cómo habéis alabado este vino llamándole hideputa?». Y Sancho reconoce: «confieso que conozco que no es deshonra llamar hijo de puta a nadie, cuando cae debajo del entendimiento de alabarle» (II, 13). Ver al respecto Tabernero (2016: 264).

14. Sancho está dispuesto a «disimular cualquiera injuria, porque tengo mujer y hijos que sustentar y criar. Así que, séale a vuestra merced también aviso, pues no puede ser mandato que en ninguna manera pondré mano a la espada, ni contra villano ni contra caballero; y que, desde aquí para delante de Dios, perdono cuantos agravios me han hecho, y han de hacer, ora me los haya hecho, o haga o haya de hacer, persona alta o baja, rico o pobre, hidalgo o pechero, sin eceptuar estado ni condición alguna» $(\mathrm{I}, 15)$. 
no debes de ser de Miguelturra, sino algún socarrón que, para tentarme, te ha enviado aquí el infierno. Dime, desalmado, aún no ha día y medio que tengo el gobierno, y ¿ya quieres que tenga seiscientos ducados? (II, 47).

No faltan improperios por parte de Sancho a otros personajes. Unos referenciales, como los que dirige, entre otros, contra la sublimada Dulcinea, que, según sus palabras «es moza de chapa, hecha y derecha y de pelo en pecho, y que puede sacar la barba del lodo a cualquier caballero andante o por andar, que la tuviera por señora. ¡Oh hideputa, qué rejo tiene, y qué voz!» $(\mathrm{I}, 25)$; o bien la llama "borrega mansa: es más blanda que una manteca" (II, 12). También hacia los personajes mágicos de la novela, como los gigantes ["ese hideputa dese gigante" (I, 29)], los encantadores "aciagos" que hacían la vida imposible a su amo y a él mismo: "malintencionados", "bellacos" (II, 10) y "malandrines" (II, 56). O al "embustero" "grandísimo maleador", Ginés de Pasamonte (II, 4). Otros, como ya hemos visto, son conatos directos: a su mujer, Teresa Panza, a quien trata de "boba" o le impreca con un "Ven acá, bestia y mujer de Barrabás", "animalia"; "Ven acá, mentecata e ignorante (que así te puedo llamar, pues no entiendes mis razones y vas huyendo de la dicha)" (II, 5). Así lo hace también con los criados de los duques que lo persiguen para bañarlo y aderezarlo; "sois malos y mal nacidos", "malandrines" (II, 32). Sin olvidar otras expresiones utilizadas por el escudero en cuentos e historias: el cosmógrafo Ptolomeo del que le habla don Quijote se convierte, en la boca trabucada de Sancho, en "puto y gafo, con la añadidura de meón o meo"; en el cuento en el que un labrador discute con un hidalgo sobre quién debía tomar la cabecera de la mesa, es el hidalgo quien le trata de "majagranzas" (II, 31); o el "hideperro" Cide Hamete Benengeli, moro para más señas, que había mezclado "berzas con capachos", al introducir la novela El curioso impertinente dentro de la primera parte del Ingenioso (II, 3).

Pero incluso entonces, los insultos de Sancho se dirigen a personas que no tienen un estado social superior. Nobles o eclesiásticos [salvo el desagradable clérigo servidor de los duques a quien el escudero trata despectivamente de "hombrecito" (II, 32)] quedan al margen del improperio directo, que se restringe a aquellos con quienes comparte estatus, manteniendo el respetuoso decoro hacia la estructura social, incluso cuando él logra alcanzar, durante un corto lapso de tiempo, el glorioso y cargoso puesto de gobernador; pues, a pesar de todo, no olvida quién es, de dónde procede y sus propias limitaciones de escudero simplón.

\section{3. ¿QUIÉNES INSULTAN AL HIDALGO Y AL ESCUDERO, QUE NO SEAN ELLOS MISMOS?}

Probablemente el hidalgo y su escudero se bastan ellos para insultar e insultarse, pero también son el objeto de los denuestos de otros personajes. 
Es presumible que las más duras y despectivas invectivas que recibe el hidalgo sean las de una dama, de nombre rimbombante, Altisidora, que se ha visto rechazada por don Quijote, después de sus eróticas zalamerías en la misma alcoba del caballero:

¡Vive el Señor, don bacallao, alma de almirez, cuesco de dátil, más terco y duro que villano rogado cuando tiene la suya sobre el hito, que si arremeto a vos, que os tengo que sacar los ojos! ¿Pensáis por ventura, don vencido y don molido a palos, que yo me he muerto por vos? Todo lo que habéis visto esta noche ha sido fingido; que yo no soy mujer que por semejantes camellos había de dejar que me doliese un negro de la uña, cuanto más morirme (II, 70).

A las que después añade expresiones como "malandrín mostrenco" o se refiere a su "fea y abominable catadura".

El resto, no lo son tanto, y vienen a repetir los denuestos habituales, "mentecato" (II, 16, 18, 62), loco (II, 17, 18, 62, 65, 66), don Tonto (II, 31), procedentes del caballero del Verde Gabán, de un castellano en Barcelona, de eclesiásticos y de otros hidalgos, y, en algunas ocasiones, especialmente cuando no es reconocido como caballero, por cuadrilleros, lanceros o molineros. Ante tales improperios, el Quijote actúa con el desprecio y desdén del que se sabe superior. Así responde a los arrieros:

Pero de vosotros, soez y baja canalla, no hago caso alguno: tirad, llegad, venid y ofendedme en cuanto pudiéredes, que vosotros veréis el pago que lleváis de vuestra sandez y demasía (I, 3).

Los principales insultos que recibe Sancho son por parte de aquellos que habían sido afectados por algunas de las acciones y aventuras del hidalgo - es decir, todos-, como el barbero al que habían robado los aparejos del asno y el bacín o yelmo de Mambrino, y que llama a Sancho "ladrón"; la dueña de los duques, que enciende en cólera y trata de "hijo de puta" a Sancho por tratarla de vieja (II, 31); o las indignadas sobrina y ama del hidalgo (II, 2). Sancho es el "comilón" (II, 72), "saco de maldades" (II, 2), "destripaterrones" (II, 5), "porro" (II, 52). Y, como en el caso de don Quijote, es una mujer, además de la suya, quien lanza sobre el pobre escudero los peores insultos. En efecto, es la ninfa que acompaña a Merlín en la fantasiosa comedia que se representa en el palacio de los duques, cuando este ofrece como solución al desencantamiento de Dulcinea que el escudero reciba tres mil azotes. Al negarse Sancho en rotundo, se levanta la ninfa y grita:

¡Oh malaventurado, alma de cántaro, corazón de alcornoque, de entreñas guijeñas y apedernaladas! Si te mandaran, ladrón desuellacaras, que te arrojaras de una alta torre al suelo; si te pidieran enemigo del género humano, que te comieras una docena de sapos, dos de lagartos y tres de culebras; si te persuadieran a que mataras a tu mujer y a tus hijos con algún 
truculento y agudo alfanje, no fuera maravilla que te mostraras melindroso y esquivo [...] Pon, ¡oh miserable y endurecido animal!, pon digo esos tus ojos de machuelo espantadizo en las niñas destos [...] Muévate, socarrón y malintencionado monstro, que la edad tan florida mía, que aún se está todavía en el diez y... de los años, pues tengo diez y nueve y no llego a veinte, se consume y marchita debajo de la corteza [...] Date, date en esas carnazas, bestión indómito, y saca de harón ese brío, que a solo comer y más comer te inclina (II, 35).

Ambos, hidalgo y escudero, sufrirán la humillación pública organizada por los mismos duques cuando, hechos presos por un grupo de lanceros, sean llevados por el camino, en lo que puede ser una especie de injuria carnavalesca ${ }^{15}$, casi bakhtiniana, de ruido, disfraz, chanza, cantos y teatro callejero, a las voces estentóreas y públicas de:

— ¡Caminad, trogloditas! — ¡Callad, bárbaros! — ¡Pagad, antropófagos! - ¡No os quejéis, scitas, ni abráis los ojos, Polifemos matadores, leones carniceros! [A lo que responde Sancho:] — ¿Nosotros tortolitas? ¿Nosotros barberos ni estropajos? ¿Nosotros perritas a quien dicen cita, cita? (II, 68).

\section{4. ¿UN REFLEJO DE LA REALIDAD SOCIAL Y COTIDIANA?}

El uso de la injuria y de la agresión física fueron «realidades omnipresentes en las relaciones vecinales» (Mantecón Movellán 1997: 313). Desde época medieval, y especialmente en la moderna, los delitos contra el honor (Heras Santos 1991: 224) o los delitos de palabra (Villalba 1993: 179-185) tuvieron una especial presencia en los textos legislativos y, en consecuencia, en los tribunales. Entre las injurias graves, la legislación incluiría las voces gafo, sodomético o cornudo o traidor o hereje o a mujer que tenga marido puta, o otros denuestos semejantes; y livianas (Villalba 1993 179-185) que comprenderían una gran variedad de formas orales, escritas y gestuales. Palabras y gestos con una repercusión directa sobre el honor y la fama, imprescindibles para el reconocimiento social y personal.

Lo que sí podemos constatar es que estas fórmulas y modos de injuriar en la novela son similares a los que se testimonian en los pleitos judiciales por injurias. De hecho, las investigaciones que hemos realizado en los fondos del Archivo General de Navarra, reflejan esa «realidad onmipresente» del denuesto, con más de 4.100 procesos por injurias, de los cuales hemos estudiado a fondo más de 1.400 , circunscritos a los siglos XVI y XVII ${ }^{16}$. En efecto, en

15. En lo que Martí (1987-1988: 299) consideró burlas y «crueldades psicológicas» de los «representantes más altos de la clase favorecida».

16. Un ejemplo de análisis de los insultos en procesos judiciales, en este caso inquisitoriales (Ricós Vidal 2013). 
ellos se repiten ristras de injurias similares a las que don Quijote, Sancho y otros personajes utilizan. Son, por tanto, retahílas de insultos que responden a una realidad; es decir, los insultos proferidos por los personajes cervantinos, son, en buena parte, imitaciones de los socio-lenguajes de su tiempo (Illades Aguiar 2014) ${ }^{17}$.

En 1573, Antonio Bartolomé y Sebastián Martínez de Sarasa, vecinos de la localidad navarra de Villafranca, mantenían una disputa sobre si Sebastián podía utilizar un camino que cruzaba una pieza de la cofradía de Santa María para llegar a sus propias piezas. Un día, por esta razón, comenzaron a discutir públicamente $\mathrm{y}$, según los testigos, Bartolomé le dijo a Sebastián que era "un bellaco, villano, cornudo, harto de ajos"18. Juan de Mendívil era colector de las bulas de redención de cautivos y en 1527 reclamó a Johan de Tux, vecino de Puente la Reina, el pago una de ellas. Entonces comenzó una disputa en la cual, según los testigos, Tux le dijo a Mendívil: "hi de puta, bellaco, judío, falsario de las bulas y, para esta saliréis de aquí". O bien "Hi de puta, borracho"19.

Es más, las declaraciones de los testigos en estos pleitos, nos ayudan a entender el porqué o al menos a encontrar una justificación del uso de palabras airadas del caballero contra su escudero. En efecto: el caballero está autorizado socialmente para utilizar unas palabras que no debieran considerarse injuria, sino corrección del superior al inferior, y como tal, algo comprensible. ¿Podía sentirse infamado Sancho? Una testigo afirmaba en un pleito de 1550 del lugar de Ororbia que «se usa y acostumbra decir por vía de corrección» que las dueñas puedan insultar a sus criadas y mozas ${ }^{20}$. En el lugar de Iribas, Juanacho de Argaña y Jurdana de Aizola, las dos casadas, fueron acusadas de injuriar a la moza hidalga y costurera Juana de Lecumberri. Los testigos afirmaron que era habitual que las mujeres casadas riñesen con las mozas, y las casadas «por vía de reprensión las ultrajan, pero que por ello las tales mozas no quedan deshonradas ni ofendidas en sus honras». En esta misma causa el rector de las parroquias de Alli y Eraso, don Juan Périz de Lecumberri, aseguró que a él mismo «le han tratado de bellaco, traidor y falso y logrero y muchas palabras sucias y feas», pero él no se había «tenido jamás por afrontado ni ofendido, ni infamado en su honra», «por ser como dicho tiene el común hablar de la tierra». Y un notario decía que una mujer casada o un hombre de bien podían utilizar tales palabras injuriosas contra una moza o un mozo, «por manera de reprensión y castigo» y no por ello quedaban difama$\operatorname{dos}^{21}$. Sancho no responde airado, sino que acepta resignado, no indiferente, una práctica que estaba, teóricamente, aceptada por la sociedad. Pero la realidad es cambiante y se demuestra que todos, hidalgos o no, casados o no,

17. O, si se quiere, un ejemplo de «mímesis conversacional» (Gómez 2004).

18. Archivo General de Navarra [AGN], Tribunales Reales. Procesos, núm. 146635.

19. AGN, Tribunales Reales. Procesos, núm. 280002.

20. AGN, Tribunales Reales. Procesos núm. 293990.

21. AGN, Tribunales Reales. Procesos, núm. 9689. 
pobres o no, acudieron a los tribunales para defender su dignidad, asumiendo como comunes unos valores que querían ser patrimonializados por unos.

Además, ese respeto a la estructura social casi reverencial en el uso del insulto que se hace en el Quijote, no se manifiesta de forma tan evidente en los procesos judiciales que estudiamos: sí en lo que hace referencia a los miembros de la aristocracia, pues apenas se dan casos de nobles de una condición media o alta; pero no hacia los hidalgos. Estos no se vieron libres de denuestos e improperios públicos que afectaban a su honor y a su condición. Los ataques a la calidad social se repiten sucesivamente. El hidalgo Johanot de Aldunate vivía honestamente, como tal, en Artaiz, hasta que un día de septiembre de 1539, cuando recogía nueces de un nogal, María de Sagaseta y su hija lo trataron de "bellaco, villano, mal cristiano e de mala vida" 22 . Martín de Izurzu, "hijodalgo notorio e indubitado y de los principales del dicho lugar", "hombre de bien y buen cristiano", el 4 de agosto de 1581 iba hacia su casa y cuando pasó por la era de María de Esténoz, esposa de Juan de Esparza, donde estaban ella y su hijo, Juanes de Esparza, les saludó. Pero, como toda respuesta, estos, a voces «le dijeron que era chiflo, y así le llamaría day adelante y que era verdad que era un chiflo, a decir que era un loco, y que eran mejores que él y más principales y que era un villano y una bestia y salvaje y asno». Cuando, sin embargo, Esténoz y su familia era labradores «de su origen y dependencia y descendientes de una casa labradora del lugar de Esparza y de diferente cualidad que el suplicante, [...] en lo cual injuriaron al suplicante atrozmente y delinquieron por ello gravemente» ${ }^{23}$.

\section{BREVES REFLEXIONES}

A lo largo de estos párrafos hemos perfilado los retazos del uso novelesco y cotidiano de las injurias. Por supuesto que en sus capítulos hay otros personajes que improperan y son denostados, pero no serán tratados en esta ocasión. Tampoco nos hemos ocupado aquí de otras cuestiones de gran interés como los efectos de la injuria sobre el honor y la honra, sobre las circunstancias en las que se manifestaban, los principales protagonistas o cómo son aspectos léxicos que escapan a nuestra competencia. A pesar de ello, creo que se ha podido demostrar cómo en el Quijote el uso de los insultos por, hacia $\mathrm{y}$ entre sus dos personajes principales, mantiene un estilo conforme a lo que son y representan. El viejo hidalgo usa los insultos con una función conativa y expresiva, especialmente hacia su escudero, un estilo directo, que humilla y en el cual se establecen y fijan las fronteras de la diferencia social.

El escudero apenas osa utilizar la injuria de la misma manera que su amo: este, un hidalgo, solo recibirá por parte de su simple criado insultos indirectos, 
que, en la mayoría de las ocasiones, Alonso Quijano ni oye ni percibe de la boca de Sancho. El escudero, sin embargo, sí utilizará los improperios de la misma manera que el caballero de la Triste Figura, cuando los receptores son sus iguales y, especialmente, cuando logre un repentino y breve ascenso social que le permita mostrarse superior en autoridad y gobierno a todos ellos cuando hasta entonces, como reconocía su mujer Teresa, todos lo tenían por un "porro" (II, 52).

Este uso selectivo del insulto, sin embargo, no se refleja en los testimonios reales. Sí es cierto que la mayoría de los improperios que aparecen a lo largo de la novela eran de uso cotidiano y habitual, con largas, originales y destructoras sartas de la honra de sus receptores. Es cierto también que algunos justificaban el uso del insulto como corrección siempre y cuando fuese proferido desde una posición social superior en todas sus variantes; pero esto no fue en modo alguno aceptado por los injuriados imbuidos de un espíritu de defensa de la honra por encima del estamento. Sin embargo, ese respeto hacia el hidalgo, si nos circunscribimos estrictamente al uso del insulto en la novela - otra cosa son las aventuras en las que el hidalgo y caballero andante aparece como un personaje ridículo-, no se hizo palpable - a pesar de que los tribunales intentaron protegerlo, sin éxito-, pues el hidalgo, el hidalgo corriente de las ciudades, villas y lugares, no se diferenciaba tanto en su forma y estilo de vida de la del resto de sus convecinos pecheros y labradores.

Por otra parte, en el Quijote las injurias no acaban en pleito, a diferencia de lo que ocurría en aquella sociedad de pleiteantes (Kagan 1991). Quizás porque, como advierte el propio caballero, "el que no puede ser agraviado, no puede agraviar a nadie" (II, 32). Y, ¿hasta qué punto pueden agraviar o ser agraviados un loco y un simple? Juana de Etayo, vecina de Murieta, fue acusada en 1596 de injuriar a la viuda Catalina Martínez. Sin embargo su procurador la disculpó porque desde hacía un año Etayo estaba «frenética y falta de juicio y de memoria y que en tiempos interpolados y variación dellos y en conjunciones y mudanzas de luna está frenética, aunque no hace mal con las manos sino solo hablar». Y, como señalaba más adelante el abogado, después de que los testigos confirmaran que adolecía de «flaqueza de cabeza»: «Una persona faltosa de juicio no puede injuriar ni agraviar a otra» ${ }^{24}$.

Ciertamente el estudio de la injuria, de su uso cotidiano y literario, es un magnífico instrumento para la percepción general de actitudes y cambios sociales y, como apuntábamos con anterioridad, para apreciar determinados sistemas de valores. Pero, quizás, como historiadores, con este texto, hemos mancillado la obra. Como advertía al final de la novela el narrador Cide Hamete Benengeli al colgar su pluma: “Aquí quedarás, colgada desta espetera y deste hilo de alambre, ni sé bien cortada o mal tajada péñola mía, adonde vivirás luengos siglos, si presuntuosos y malandrines historiadores no te descuelgan para profanarte" (II, 74). Quiera Dios, que no haya sido así. 


\section{BIBLIOGRAFÍA CITADA}

Burke, Peter (1987). The Historical Anthropology of Early Modern Italy: Essays on Perception and Communication. Cambridge: Cambridge University Press.

Burke, Peter (1989). "L'art de l'insulte en Italie aux XVIe et XVIIe siècles», en Jean Delumeau (ed.), Injures et Blasphemes. Paris: Imago, pp. 49-62.

Cash, Annete G. (2008). «Formas de tratamiento en "Don Quijote"», en Alexia Dotras, Tus obras los rincones de la tierra descubren. Actas del VI Congreso Internacional de la Asociación de Cervantistas. Alcalá de Henares: Centro de Estudios Cervantinos, pp. 225-232.

Castillo Lluch, M. (2004). «De verbo vedado: consideraciones lingüísticas sobre la agresión verbal y su expresión en castellano medieval», Cahiers de linguistique hispanique médiévale. 27 (1), pp. 23-55, doi: https://doi.org/10.3406/cehm.2004.1609.

Cervantes Saavedra, Miguel de (2004). Don Quijote de la Mancha, Francisco Rico (ed.). Madrid: Real Academia Española.

Gómez, Jesús (2004). «Pláticas y coloquios en el "Quijote"», Anales Cervantinos. 36, pp. 247-278.

Heras Santos, José Luis (1991). La justicia penal de los Austrias en la Corona de Castilla. Salamanca: Universidad.

Herrero Ruiz de Loizaga, F. Javier (2013). «El insulto en obras dialogadas de los siglos XVI y XVII», en Carmela Pérez-Salazar, Cristina Tabernero y Jesús M. Usunáriz, Los poderes de la palabra. El improperio en la cultura hispánica del Siglo de Oro. New York: Peter Lang, pp. 149-173.

Illades Aguiar, Gustavo (2014). «La "ecuación oralidad-escritura” en las letras hispánicas siglos XV-XVII (propuestas en torno a un diálogo en ciernes)», Criticón. 120-121, pp. 155-170, doi: https://doi.org/10.4000/criticon.872.

Kagan, Richard (1991). Pleitos y pleiteantes en Castilla, 1500-1700. Valladolid: Junta de Castilla y León.

Kudaka Watanabe, Miguel E. (1999). «La asnificación de Sancho Panza en la segunda parte del Quijote», Lexis. 1, pp. 125-136.

Mantecón Movellán, Tomás A. (1997). Conflictividad y disciplinamiento social en la Cantabria rural del Antiguo Régimen. Santander: Universidad de Cantabria.

Martí, Antonio (1987-1988). «Mal y violencia en "Don Quijote": crítica social cervantina», Anales Cervantinos. 25-26, pp. 285-303.

Ricós Vidal, Amparo (2013). «De injurias y blasfemias: insultos y otros actos descorteses en los procesos inquisitoriales de los siglos XVI y XVII», en Carmela Pérez-Salazar, Cristina Tabernero y Jesús M. Usunáriz (coord.), Los poderes de la palabra. El improperio en la cultura hispánica del Siglo de Oro. New York: Peter Lang, pp. 231-244.

Sheridan, Guillermo (2007). Paralelos y meridianos. México: DGE Ediciones.

Tabernero, Cristina (2010). «Injurias, maldiciones y juramentos en la lengua española del siglo XVII», Revista de Lexicografía. XVI, pp. 101-122.

Tabernero, Cristina (2016). «Anti-modelos sociales e insultos en la Navarra del Siglo de Oro: de bellacos a pícaros», en Ignacio Arellano (ed.), Modelos de vida y cultura en la Navarra de la modernidad temprana. New York: Idea, pp. 251-279.

Torres, Bénédicte y Estela-Guillemont, Michèle (2008). «Algunas consideraciones acerca de la violencia en el "Quijote"», en Alexia Dotras (coord.), Tus obras los rincones de la tierra descubren: actas del VI congreso internacional de la Asociación de Cervantistas. Alcalá de Henares: Centro de Estudios Cervantinos, pp. 719-746. 
Usunáriz, Jesús M. (2005). «Presentación», en Rocío García Bourrellier y Jesús M. Usunáriz (ed.), Aportaciones a la historia social del lenguaje: España siglos XIV-XVIII. Madrid: Iberoamericana, pp. 13-25.

Usunáriz, Jesús M. (2008). «Cuando la convivencia es imposible. Los pleitos de discordia entre padres e hijos (Navarra, siglos XVI-XVII)», en Jesús M. Usunáriz y Rocío García Bourrellier (ed.), Padres e hijos en España y el mundo hispánico: siglos XVI y XVIII. Madrid: Visor, pp. 207-244.

Usunáriz, Jesús M. (2010). «La violencia doméstica en la España de los siglos XVI y XVII: el ejemplo del reino de Navarra», en Juan Manuel Escudero y Victoriano Roncero (ed.), La violencia en el mundo hispánico en el Siglo de Oro. Madrid: Visor, pp. 375-394.

Usunáriz, Jesús M. (2016). «Los fundamentos de la nobleza y las ofensas, infamias e injurias contra el linaje en los siglos XVI y XVII», en David García Hernán y Miguel F. Gómez Vozmediano (ed.), La cultura de la sangre en el Siglo de Oro. Entre Literatura e Historia. Madrid: Sílex, pp. 65-93.

Villalba, Enrique (1993). La administración de la justicia penal en Castilla y en la Corte a comienzos del siglo XVII. Madrid: Actas.

Recibido: 15 de junio de 2016

Aceptado: 3 de julio de 2017 